\title{
Historieämnets legitimitet i en postmodern tid
}

\section{Av Roddy Nilsson, FD i historia}

\author{
Länk till presentation av Roddy Nilsson
}

Varför ska historia finnas på schemat i grundskola och gymnasium? Varför ska det vara möjligt att läsa historia på universitet och högskolor? De här frågorna liksom den ännu större dito om varför vi över huvud taget ska bry oss om historien kan ges många olika typer av svar. Ett sätt är att se dem i ljuset av en diskussion kring legitimitetsproblematiken. Jag ska i den här korta artikeln lyfta fram och diskutera några, som jag ser det, viktiga utgångspunkter och förutsättningar för att kunna formulera en legitimitet för historieämnet.

Begreppet legitimitet har spelat en viktig roll i den moderna samhällsvetenskapen. Som Ola Agevall visar i sin diskussion ovan kan frågan om legitimitet angripas från flera olika håll.[1] Jag kommer avslutningsvis att med hjälp av de variabler Agevall urskiljt som grundläggande för en analys av legitimitetsförhållanden skissera en tentativ bild av de olika svar som jag menar att moderniteten respektive postmoderniteten ger på dessa frågor. Jag kommer dock att inleda med en kort diskussion kring vad jag mera generellt ser som centralt när det gäller syftet med historiska studier.

Utgångspunkten för mig är insikten att vi lever i postmoderniteten vilket medför en förändrad erfarenhetsvärld i jämförelse med moderniteten. Detta i sin tur har betydelse för hur historieämnet kan och bör legitimeras. Det medför också att förutsättningarna för kunskapsproduktion och kunskapsöverföring både i teknisk och social bemärkelse har förändrats kraftigt.[2]

Postmoderniteten har i slutet av det 20:e århundradet ersatt moderniteten som dominerande kulturell konfiguration vilken tagit sig uttryck i en rad sociala, ekonomiska, politiska och teknologiska förändringar. Att moderniteten ersatts av postmoderniteten ska inte ses som ett absolut brott. Tvärtom kan det hävdas att postmoderniteten innehåller och på vissa områden fört med sig en radikalisering av företeelser och tendenser som utmärkte moderniteten. Här finns emellertid inte utrymme för någon ytterligare diskussion kring innebörden i dessa förändringar vilka jag utförligare diskuterat i andra sammanhang.[3]

\section{I}

För att kunna skapa ett historieämne som både är samtida och återknyter till sin egen äldre historia måste vi göra oss av med det mesta av ämnets modernistiska barlast; dess objektivitets- och neutralitetsideal, dess realistiska kunskapssyn och sanningsanspråk, dess avståndstagande från all form av historiefilosofi; dess framstegstänkande, dess monopol på en sorts rationalitet etc. Vi bör dock behålla den dialogiska potential som finns slumrande i moderniteten - även om vi inte tror på vare sig Habermas eller hans ideal kanske vi ska handla och tänka som om vi gjorde det. Historieundervisningen måste - även i praktiken erkänna att den alltid är för någon, att den utformas med ett syfte i åtanke. Den syn på historien och historieämnets legitimering jag här pläderar för vänder sig emot tanken på ett studium av historien för dess egen skull - att studiet skulle ha ett egenvärde som inte i sig behöver ytterligare motiveras.

För mig är det centralt att historieämnet måste kunna spela en roll både i nuet och i framtiden. Det är viktigt att studenterna upplever att historiestudiet är relevant och betyder 
något för dem i nuet. Historia bör vara en reflexiv och praktisk aktivitet. Historias största betydelse ligger inte i förmedlandet av faktakunskaper om det förflutna utan i dess potential att förändra vår världsbild - vår syn på samtiden och på vad människan är och kan bli. I förlängningen av detta ligger också att historia kan skapa möjligheter till förändring, antingen politiskt, socialt eller på ett individuellt plan. För, som Eric Hobsbawm säger, historia är det mest praktiska redskap vi har för att hantera den ständiga förändring vi är underkastade.

Historien kan verka befriande från samtidens bojor. Den kan erbjuda oss alternativ och visa att något skulle kunna förhålla sig annorlunda. Det handlar om att låta historia bli ett verktyg för studenterna för att förstå sig själva och sin samtid; vem man är och vad man kan bli; det handlar om identitet och självkännedom; om att lära sig mera om andra kulturer och samhällen genom att studera andra epoker; det handlar om en historia som kan fungera i en tid där en ny individualism växer fram. Det handlar om att historia ska hjälpa människor att bli och vara någon i en svåröverskådlig och allt mera krävande tid. Det handlar om att kunna fungera utifrån de behov och erfarenheter studenten har; om att utrusta honom eller henne med redskap för att kunna hantera sitt eget liv. Med ett i sammanhanget vanligt engelskt ord brukar det sistnämnda beskrivas som "empowerment".[4]

Postmoderniteten innebär bl a ett accepterande och - menar jag - bejakande av det mångkulturella. Något som får viktiga konsekvenser inte minst för historieutbildningen. Hans Ingvar Roth diskuterar i en artikel mångkulturalismens betydelse för den svenska skolan. Roth delar in ämnena i tre olika kategorier: kulturellt neutrala, kulturspecifika och mångkulturella profilämnen. [5] Historia hänförs till den sistnämnda kategorin vilken omfattar ämnen som berör olika gruppers historiska och samtida roll i samhället. Betoningen på historias mångkulturella karaktär innebär att olika gruppers perspektiv integreras i undervisningen. Detta har framför allt tagit sig uttryck i målsättningen att olika minoriteters erfarenheter ska lyftas fram.

Roths artikel behandlar situationen i grundskola och gymnasium. Det är här diskussionen om mångkulturalism börjat göra sig gällande. Jag anser dock att det är dags att utvidga diskussionen till att också omfatta den undervisning och forskning som bedrivs vid högskolor och universitet. Om inte vi som arbetar med historia tar denna utmaning på allvar riskerar ämnet i värsta fall att bli förbehållet etniska "svenskar". Varför har - till skillnad från vad som är fallet inom naturvetenskap och teknik - en försvinnande liten del av historiestudenterna invandrarbakgrund? Beror det på ofullständiga kunskaper i svenska, ointresse eller kan det vara så att studenter med invandrarbakgrund uppfattar historia i termer av vad Roth kallar ett kulturspecifikt ämne, d v s att undervisningen i historia inte är undervisning om historia utan $i$ ? Alltså i detta fall i "svensk" historia vilken de inte uppfattar är till för dem? Är det kanske denna effekt mycket av historieundervisningen i grundskola och gymnasium i praktiken har lett till? Det är dock viktigt att framlyftandet av det mångkulturella inte utvecklas till att bli ett redskap i någon form av "culture war" i miniatyr efter amerikansk modell.[6]

\section{II}

Historia måste, menar jag, för att stärka sin legitimitet i det tjugoförsta århundradet både betona - och bejaka - sin extremt samtidsberoende karaktär och knyta tillbaka till sin egen historia, alltså till vad som brukar benämnas historiografin. Om vi gör det sistnämnda kommer vi också att åter kunna lyfta upp två av historiestudiets länge undanträngda delar, nämligen dels vad modernitetens historiker ofta nedlåtande och med tydligt avståndstagande kallat "historiefilosofi", dels dess potential att kunna vara till hjälp i ett moraliskt reflexivt tänkande. Historia måste, för att tala med den brittiske historikern Beverley Southgate, få en injektion av filosofi.[7]

Studiet av historia måste i sista hand vara ett medel för insikt i och reflektion över vad som 
pretentiöst brukar kallas de "stora" eller "eviga" frågorna (som inom parentes sagt inte alls är eviga utan konstruktioner av de problem som upplevs som angelägna vid ett visst tillfälle). Det bör betonas att när jag talar om att historien måste bli mera filosofisk så handlar inte detta om teleologisk spekulation à la Hegel, Marx, Spengler eller Fukuyama. Medan historiefilosofin av nyss nämnda slag kan sägas gå ut på att avslöja eller deducera fram "historiens mening" handlar det här i stället om att studiet av historia kan vara en hjälp för hur vi lever våra liv.

Historia som magistrae vitae, som "livets lärare", har en lång tradition. Fram till genombrottet för den moderna historieskrivningen decennierna kring sekelskiftet 1900 och inriktningen på källkritik och faktapositivism betonades det hur studiet av historien kunde ge samtiden instruktiva och eftersträvansvärda exempel på moraliskt och dygderikt handlande. Detta kombinerades oftast med en starkt individcentrerad historiesyn där det var den enskilde hjälten (krigaren, kungen, statsmannen etc.) eller någon gång hjältinnan som stod i fokus. Den moderna historieskrivningens källkritikbaserade sanningssökande ledde emellertid till att vad vi kan kalla "historien som moraliskt exempel" avvisades på programmatiska grunder. Historikern hade inget särskilt ansvar för att undervisa samtiden om dygderika exempel från det förflutna. Hans ansvar och professionalism låg i sökandet efter sanningen, i att visa "wie es eigentlich gewesen". I den skarpast formulerade faktapositivismen sågs moraliska frågor som meningslösa och ovetenskapliga och följaktligen som något som historikern inte borde syssla med.

\section{III}

Av övertygelsen att studiet och förmedlingen av historien har - eller kan ha - en enorm betydelse för hur vi lever våra liv följer också ett moraliskt ansvar. Postmodernitetens betoning på att det inte finns någon värdeobjektiv eller neutral historieskrivning innebär inte ett mindre moraliskt ansvar utan ett större. Historien i sig innehåller inga lärdomar eller svar på moraliska frågor. Den kan bara vara grundmaterial och utgångspunkt för historiska reflexioner.

En postmodernistisk historieskrivning flyttar fokus från historien till historikern på samma sätt som den postmoderna historieundervisningen flyttar fokus från stoffet till läraren. Det är historikern/läraren - eller med andra ord förmedlaren/producenten av historien - som har ansvar för vad det forskas eller undervisas kring. Det finns inga givna svar på frågor vad historien ska handla om. Det finns inga "stora" eller "viktiga" problem eller processer som framträder av sig själva. Historien är alltid ett val. Det är i sista hand också här historikerns och historielärarens ansvar ligger. Samtidigt innebär detta ett större ansvar för studenten. Denne måste vara beredd att själv ta sitt ansvar för vad han eller hon lär sig och för hur historien används.

I insikten om att studiet av historia och andra former av kulturstudier kan spela en central roll kan man hämta stöd från så olika tänkare som Michel Foucault och Martha Nussbaum. För Foucault framstod historien, framför allt under de sista åren av hans liv, som ett område där den av erfarenheten formade verkligheten och gränserna för den mänskliga existensen möttes. Foucault kallar på ett ställe historien för "a critical ontology of ourselves".[8] Nussbaum pläderar för en hållning där utbildningen formas till ett fritt kunskapssökande med målsättningen att öka vår förmåga både till självreflexion och till att se oss i ett större mänskligt sammanhang.[9]

\section{IV}

Syftet med denna artikel är att betona att historieämnets legitimitet idag måste vara en annan än den som gällt under den moderna epoken. Med historieämnet avses här undervisningsämnet historia, framför allt inom högre utbildningar. Diskussionen gäller därmed inte explicit legitimeringsgrunderna för forskningsämnet historia. Frågan om, och i så fall hur, legitimeringsgrunderna för undervisningsämnet historia skiljer sig från 
forskningsämnet historia tas inte upp här. Jag skulle dock hypotetiskt vilja hävda att skillnaden beträffande legitimeringsgrunden för historia som undervisning och historia som forskning tenderar att bli mindre i och med postmodernitetens intåg. Jag menar alltså att ett postmodernistiskt synsätt innebär ett betydligt närmare förhållande mellan forskning och undervisning än ett modernistiskt. Det ska också understrykas att de diskussioner och kontroverser som finns mellan forskarna har stor betydelse för hur dess förmedling ser ut. De försök i "back to the essentials-anda" som kunnat iakttas är därför inte bara något som rör forskningen inom ämnet utan också historieförmedlingen i dess olika former.[10] Det är dock fullt klart att en uppdelning av historieämnet i undervisning och forskning inte täcker alla de former detta kan uppträda i.

Med utgångspunkt i de variabler Agevall diskuterar skulle en tentativ uppställning över historieundervisningens legitimitetsförhållanden inom moderniteten respektive postmoderniteten kunna se ut som nedan. På frågan vad som erkändes (som historia) under moderniteten låg betoningen på stoffet och den (realistiska) narrativa formen. Centralt var också erkännandet av historia som ett specifikt ämne. I postmoderniteten står erkännandet av historia som en kunskapsform, ett redskap för reflexion, i centrum. När det gäller vem som åstundade erkännandet var det för moderniteten i första hand den i ämnet utbildade läraren medan motsvarande erkännande inom postmoderniteten gäller historieförmedlaren i bredare bemärkelse. Vems eller vilkas erkännande ansågs eller anses då nödvändigt?

Modernitetens svar på denna fråga var i första hand staten i dess olika framträdandeformer, i andra hand den bildade medelklassen. Postmodernitetens svar vill jag framför allt se som studenterna och andra "användare" av historia. Här kan möjligen också marknaden föras in i resonemanget i det att ett marknadsmoment blivit allt mera framträdande när det gäller om man över huvud taget ska välja att studera historia. Historia måste alltså i viss mån "säljas" i konkurrens med andra ämnen på ett annat sätt än tidigare. Slutligen då frågan om vilka principer man hänvisar eller hänvisade till för att få legitimitet. För moderniteten framstod fostran och bildning som de centrala kriterierna. För postmoderniteten framstår däremot de centrala principerna som "empowerment" och vad jag vill kalla moralisk vägledning.

Tablå 1. Historieämnets legitimitet.

\begin{tabular}{|l|l|l|}
\hline & Modernitet & Postmodernitet \\
\hline Vad erkänns? & Stoff, ämne & Redskap för reflexion \\
\hline Vem åstundar erkännandet? & Läraren & Förmedlaren, producenten \\
\hline Vems erkännande åstundas? & Staten, medelklassen & Användaren, Marknaden \\
\hline Vilka principer hänvisas till? & Fostran, bildning & Empowerment, moralisk vägledning \\
\hline
\end{tabular}

En tablå av det här slaget blir med nödvändighet en förenkling och renodling. Övergången från modernitet till postmodernitet innebär självklart inte att betydelsen av t ex stoffet försvunnit, bara att den minskat och kanske också ändrat karaktär. Det betyder också att det går att hitta flera aktörer, faktorer, principer etc. att placera i de olika rutorna. Syftet är att på samma gång tentativt och analytiskt försöka urskilja de "idealtypiska" svaren på de olika frågor om legitimiteten som kan ställas. Det är som Agevall framhåller i sitt inlägg viktigt att ha i minnet att dessa variabler inbördes är relaterade till varandra. Som han också mycket riktigt påpekar krävs naturligtvis mera preciserade frågor och ett empiriskt material för att kunna gå vidare.

Diskussionen om hur vi kan legitimera studiet av historia är även viktig av det skälet att det historiska perspektivet under de senaste åren fått ökad betydelse inom såväl andra kulturvetenskaper som inom samhällsvetenskaperna. Också utanför utbildningssystemet har historien mötts av ett växande intresse.

Mot dem som menar att postmoderniteten och allt vad den står för upplöser och förstör historieämnet vill jag till sist hävda att det är precis tvärtom; genom att bejaka postmoderniteten och vad den för med sig ger vi historieämnet en betydligt bättre chans än 
någonsin under moderniteten - men det är ett annat historieämne.

(C) Roddy Nilsson

[1] Se Agevall ovan.

[2] En mera utförlig diskussion kring dessa förändringar finns i Roddy Nilsson,

"Historiedidaktiken och den postmoderna utmaningen", Historisk tidskrift 1:2001 s 68-80.

[3] För en vidare diskussion av begreppet postmodernitet se Roddy Nilsson,

"Postmodernismen i historieundervisningen - hot eller löfte?", Historielärarnas förenings

årskrift 1996/1997 s 69- 79 samt Nilsson 2001 och där anförda hänvisningar.

[4] I direkt översättning från engelskan står begreppet för (att) "bemyndiga", "tillåta" eller

"göra det möjligt för" någon att göra något. Se Prismas engelska ordbok. Inom postmodern kulturteori har begreppet dock en starkare innebörd och används ofta i sammanhang när tidigare maktlösa eller svaga grupper eller individer ges legala eller intellektuella resurser för att stärka sin ställning och förbättra sina möjligheter att leva ett mera värdigt liv. Det är i denna senare bemärkelse begreppet används i denna framställning.

[5] Hans Ingvar Roth, "Skolan utmanad. Att hantera det mångkulturella", Tvärsnitt 1:2001. Gränserna mellan kategorierna kan ifrågasättas. Feminister och "postinfluerade" teoretiker har t ex hävdat att matematiken och fysiken vilka kan ses som idealtypen för kulturellt neutrala ämnen med universella begreppssystem också är impregnerade av manliga och eurocentristiska normer.

[6] Se t ex James Davidson Hunter, Culture Wars. The Struggle to Define America, New York 1991; N J Rengger, Retreat from the Modern. Humanism, Postmodernism and the Flight from Modernist Culture, London 1996; Gary B Nash, Charlotte Crabtree, and Ross E Dunn, History on Trial. Culture Wars and the Teaching of the Past, New York 2000. [7] Beverley Southgate, History: What \& Why?, London and New York 1996, s 1. För en plädering för en filosofisk ansats i studiet av historien se Gordon Graham, The Shape of the Past, Oxford and New York 1997.

[8] Michel Foucault, Politics, Philosophy, Culture: Interviews and Other Writings of Michel Foucault, New York 1988, s 95. Det är dock värt att understryka att Foucault under hela sitt liv var en tänkare - även under hans mest strukturalistiska period - för vilken historien spelade en central roll.

[9] Martha C Nussbaum, Cultivating Humanity. A Classical Defense of Reform in Liberal Education, Cambridge, Mass and London 1998.

[10] Se t ex Richard J Evans, Till historiens försvar, Stockholm 2000. 